\title{
Clustering of States of Azerbaijan Electric Power Industry's Security for Medium-Term and Long-Term Periods
}

\author{
Valeh Nasibov
}

\begin{abstract}
The paper discusses the validation of states' number of Azerbaijan electric power industry's security for medium-term and long-term periods. According to the developed simulation model the data array of electric power industry security has been obtained, on which the clustering has been carried out and 4 centers of states of electric power industry's security have been found.
\end{abstract}

Index Terms-Energy security, indicators, membership function, clustering.

\section{INTRODUCTION}

As it was shown in [1], the electric power industry's security for different time periods is determined by the security level of different number of subsystems of electric power industry: for short-term periods- 4 subsystems (fueling of electric power industry, electric power generation, transmission and distribution of electric power, connections with the neighboring power systems and import of electric power), for medium-term periods to the first four subsystems the fifth one-electric power consumption is added, and for long-term periods two more subsystems are added to five ones-reproduction of fixed assets and longterm development [2].

\section{ELECTRIC POWER INDUSTRY'S SECURITY FOR DIFFERENT TIME PERIODS}

It should be noted, that when the electric power industry's security assessing for different time periods, a significant character difference of initial information is, if for shortterm periods as the input values their current values are, then for medium-term and especially for long-term periods as input values the predicted values are, and therefore they represent not the specific values but a range of values, and therefore the resultant security, determined on their basis, is also a range of values.

As it is seen from the Fig. 1, the security state of $E-$-very bad" according to the area is slightly larger than of $A$ "excellent" area, which means that the security state "very bad" can occur with almost the same frequency as the security state "excellent", although the areas of specified security states for different countries differ considerably depending primarily on the level of energy supply of the

Manuscript published August 31, 2016. This work was supported in part by the Azerbaijan Scientific-Research \& Designed-Prospecting Institute of Energetics.

Valeh Nasibov has become the head of "Perspective development the electricity" department in Azerbaijan Scientific-Research \& DesignedProspecting Institute of Energetics. (e-mail: nvaleh@mail.ru). country.

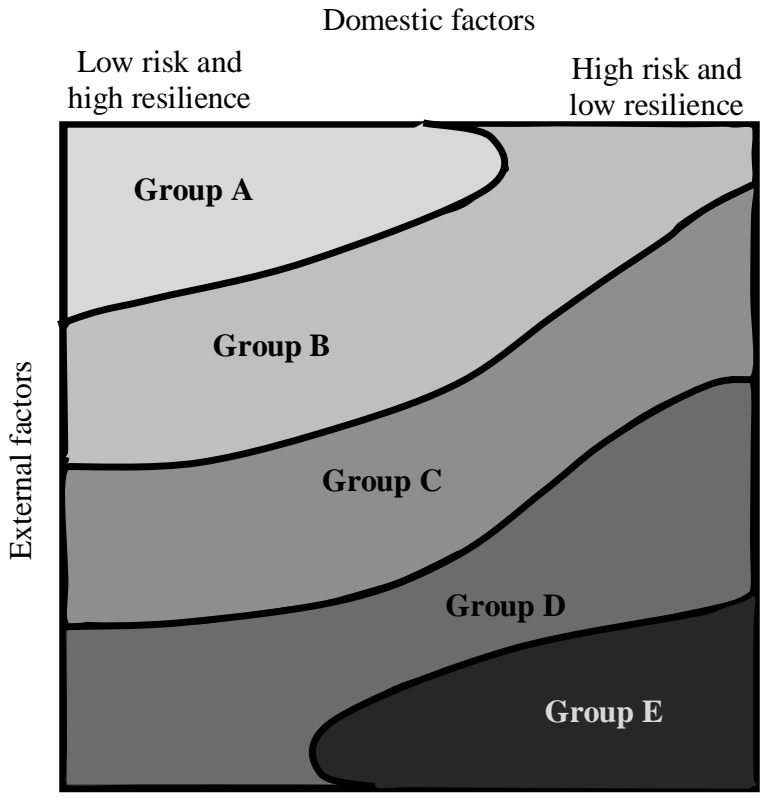

High risk and

low resilience

Fig.1 Diagram of energy security study

The problem of determining of states' number of electric power industry's security arises for medium-term and longterm periods and their occurrence probability (area of each state) for such a compact country as Azerbaijan, where the sufficient energy sources and generating capacities are.

TABLE I: CURRENT AND PREDICTED VALUES OF INDICATORS

\begin{tabular}{|l|c|c|c|}
\hline \multicolumn{1}{|c|}{ Indicators of subsystems } & $\begin{array}{c}\text { Current } \\
\text { values }\end{array}$ & $\begin{array}{c}\text { Predicted } \\
\text { values for } \\
2020\end{array}$ & $\begin{array}{c}\text { Predicted } \\
\text { values } \\
\text { for 2025 }\end{array}$ \\
\hline $\begin{array}{l}\text { SNGS -output of subsystem of } \\
\text { "Natural gas supply of the country" }\end{array}$ & 92.5 & $90-95$ & $90-95$ \\
\hline VF-variety of fuels & 0.45 & $0.42-0.47$ & $0.40-0.50$ \\
\hline$S O P$ - share of seabed mining, \% & 25 & $25-30$ & $25-30$ \\
\hline $\begin{array}{l}D P D \text {-diversification of delivery } \\
\text { ways }\end{array}$ & 0.45 & $0.42-0.47$ & $0.35-0.45$ \\
\hline $\begin{array}{l}G \text {-electric power generation by own } \\
\text { sources, \% }\end{array}$ & 100 & 100 & 100 \\
\hline$R$-reserve level, \% & 35 & $22-26$ & $22-30$ \\
\hline $\begin{array}{l}C I \text {-wear degree of capital equipment, } \\
\%\end{array}$ & 23 & $17-19$ & $16-20$ \\
\hline$W S$-wear level of substations, \% & 66 & $36-40$ & $35-42$ \\
\hline$W T$ - wear of transformers, \% & 65 & $30-35$ & $30-35$ \\
\hline$W L$-wear of air circuits, \% & 60 & $53-56$ & $50-60$ \\
\hline $\begin{array}{l}S B R \text {-balance degree of the regions, } \\
\%\end{array}$ & 65 & $70-75$ & $70-80$ \\
\hline
\end{tabular}




\begin{tabular}{|l|c|c|c|}
\hline$L I$-import level, \% & 0,1 & 0 & 0 \\
\hline$I I$ - infrastructure of import & 0.32 & 0.32 & 0.32 \\
\hline $\begin{array}{l}R M C \text {-reserve of transfer capability } \\
\text { of intersystem connections, \% }\end{array}$ & $>100$ & $20-30$ & $20-30$ \\
\hline$D O O$-duration of switching-offs, h. & 24 & 20 & 20 \\
\hline $\begin{array}{l}P A I \text { - share of average income per } \\
\text { capita, spent for electric power, \% }\end{array}$ & 3 & $2-4$ & $2-4$ \\
\hline $\begin{array}{l}R D E \text { - relative decline of electric } \\
\text { power consumption at the expense of } \\
\text { energy saving, \% }\end{array}$ & 2 & $2-3$ & $2-4$ \\
\hline $\begin{array}{l}D Q M \text { - share of input generating } \\
\text { capacities for every 3 years, \% }\end{array}$ & 8 & $8-9$ & $8-10$ \\
\hline $\begin{array}{l}D E O \text { - share of input electrical } \\
\text { equipment for every 3 years, \% }\end{array}$ & 7.3 & $7-8$ & $7-9$ \\
\hline$R G$ - reserve of installed capacity, \% & 26 & $21-25$ & $21-25$ \\
\hline $\begin{array}{l}R W \text { - reserve of transfer capability of } \\
\text { intersystem connections, \% }\end{array}$ & $>20$ & $20-30$ & $20-30$ \\
\hline $\begin{array}{l}P C \text {-energy intensity, t.n.e.(ton of oil } \\
\text { equivalent) /thousands of dollars. }\end{array}$ & 0.32 & $0.29-0,31$ & $0.27-0.29$ \\
\hline
\end{tabular}

To obtain a dependence function of resultant electric power industry's security as a function of security of electric power industry's subsystems the simulation model of obtaining of numerical values (in percents) of electric power industry's security for different variations of input values (indicators for determining of security of electric power industry's subsystems) has been drawn. On the basis of obtained numerical values of electric power industry's security the regression dependences (linear and nonlinear) of electric power industry's security on the security of electric power industry's subsystems for medium-term and longterm periods have been drawn, the linear dependences are shown in 1-2 equations.

Linear model of electric power industry's security for medium-term periods- $y_{m t}$

$y_{m t}=0,1581 x_{1}+0,3050 x_{2}+0,1811 x_{3}+0,1496 x_{4}+0,1441 x_{5}$

Linear model of electric power industry's security for long-term periods $-y_{l t}$

$$
\begin{aligned}
y_{l t}=0,1754 x_{1}+0,1961 x_{2}+0,1357 x_{3}+0,1052 x_{4}+0,0894 x_{5}+ & \\
& 0,0873 x_{6}+0,1052 x_{7}
\end{aligned}
$$

Using a simulation model of obtaining of numerical values of electric power industry's security in dependence on the perspective values of input indicators the data array of electric power industry's security of Azerbaijan for medium-term and long-term periods has been obtained. The fragment of data array out of 9000 values of electric power industry's security for medium-term periods at random combinations of input indicators is presented in Table II.

TABLE II: VALUES OF ELECTRIC POWER INDUSTRY'S SECURITY

\begin{tabular}{|c|c|c|c|c|c|c|}
\hline & \multicolumn{5}{|c|}{ Values of security of electric power industry's } & $\begin{array}{c}\text { Electric power } \\
\text { industry } \\
\text { security }\end{array}$ \\
\hline № & 1 & 2 & 3 & 4 & 5 & 6 \\
\hline 1 & 95 & 17.08 & 15.51 & 17.79 & 10.62 & 30.92 \\
\hline 2 & 95 & 11.72 & 10.92 & 10.01 & 16.36 & 28.83 \\
\hline 3 & 95 & 13.94 & 13.20 & 14.42 & 17.17 & 29.30 \\
\hline
\end{tabular}

\begin{tabular}{|l|l|l|l|l|l|l|}
\hline 4 & 95 & 18.57 & 18.26 & 26.01 & 29.36 & 32.30 \\
\hline 5 & 95 & 48.73 & 40.60 & 44.02 & 39.54 & 43.58 \\
\hline 6 & 95 & 33.59 & 19.88 & 18.41 & 22.14 & 37.36 \\
\hline 7 & 95 & 30.08 & 20.09 & 22.67 & 18.22 & 38.23 \\
\hline 8 & 95 & 23.71 & 21.50 & 33.38 & 27.51 & 39.94 \\
\hline 9 & 95 & 18.66 & 38.47 & 28.88 & 38.87 & 40.79 \\
\hline 10 & 95 & 19.25 & 23.84 & 24.00 & 28.34 & 40.15 \\
\hline 11 & 95 & 29.04 & 19.20 & 31.40 & 20.92 & 40.53 \\
\hline 12 & 95 & 18.52 & 21.48 & 37.40 & 33.99 & 36.33 \\
\hline 13 & 95 & 84.61 & 79.27 & 74.12 & 80.97 & 76.43 \\
\hline 14 & 95 & 43.22 & 57.68 & 54.53 & 43.41 & 55.55 \\
\hline 15 & 95 & 59.57 & 46.11 & 62.28 & 42.71 & 61.45 \\
\hline 16 & 95 & 61.90 & 57.10 & 60.93 & 62.45 & 68.79 \\
\hline 17 & 95 & 56.85 & 44.70 & 46.04 & 55.91 & 58.86 \\
\hline 18 & 95 & 72.36 & 83.33 & 66.83 & 78.24 & 71.84 \\
\hline 19 & 95 & 79.09 & 65.87 & 84.78 & 71.45 & 73.44 \\
\hline 20 & 95 & 76.06 & 64.10 & 83.24 & 80.50 & 75.77 \\
\hline 21 & 95 & 99.88 & 85.50 & 87.71 & 92.31 & 85.32 \\
\hline 22 & 95 & 95.35 & 85.94 & 85.39 & 86.50 & 88.17 \\
\hline 23 & 95 & 90.39 & 85.04 & 91.83 & 91.81 & 90.44 \\
\hline 24 & 95 & 90.65 & 96.10 & 95.11 & 90.03 & 92.01 \\
\hline & & & & & & \\
\hline
\end{tabular}

The obtained values of electric power industry's security are the data set which is due to be clustering. There are two ways of solving the clustering problems by Matlab: finding the centers of clusters' data with using the subtractive algorithm [4] and FCM-clustering algorithm (Fuzzy Classifier Means, Fuzzy C-Means) [5]. A distinctive feature of first method is the independence on setting of the number of clusters, unlike the second method where a number of clusters is set in advance. In the first method the centers of clusters data are calculated on the basis of subtractive algorithm. A task of finding of clusters' centers is determined by this way: the objects $X=\left(X_{1}, X_{2}, \ldots, X_{n}\right)^{T}$, due to be clustered, are given, where $\mathrm{n}-$ is a number of objects. In this process each object $X_{k}=\left(x_{k_{1}}, x_{k_{2}}, \ldots, x_{k_{p}}\right)$ represents the point in the p-dimensional space of characters $(k=\overline{1, n})$. It needs to find the centers of clusters, i.e the coordinates of centers of clustered objects, specified by $X$ set.

In this method the objects are considered as the potential centers of clusters. For each object the value of so-called potential characterizing the density of location of other objects in its neighborhood is calculated. The denser the neighboring objects locate to the specified object, the greater its potential value. The potential value for $X_{k}=\left(x_{k_{1}}, x_{k_{2}}, \ldots, x_{k_{p}}\right)$ object is calculated by the formula $P\left(X_{k}\right)=\sum_{i=1, n} \exp \left(-4 \sum_{j=1, p} \omega_{j} \cdot\left(x_{k_{j}}-x_{i_{j}}\right)^{2}\right)$, where $\omega_{j}$-is a weight of $j$-th coordinate. In case, when the object is set by two characteristics, a graphic drawing of potential distribution will represent a surface resembling a mountainous relief. As the centers of clusters the coordinates of "mountain" peaks are successively chosen, 
the object with the greatest potential is assigned as a center of first cluster. Then a center of cluster as well as the closely located to it objects are eliminated from further consideration. The potentials values of remaining objects are recalculated, and again as a center of cluster the object with the peak potential value is chosen. Iterative procedure of choice of clusters' centers continues until all the objects will be eliminated.

With FCM-clustering algorithm method the clusters are presented by fuzzy sets, the boundaries between the clusters are also the fuzzy ones.

FCM-clustering algorithm assumes that the objects belong to all clusters with determined membership function (MF). Grade of membership is determined by a distance from the object to corresponding clusters' centers. This algorithm calculates iteratively the centers of clusters and new grades of membership of objects.

It is assumed that for given $K$ sets of input vectors $x_{k}$ and $N$ of assigned clusters $c_{j}$ the anyone $x k$ belongs to anyone $c_{j}$ with membership $\mu_{j k}$ to $[0,1]$ interval, where $j$ is a number of cluster and $k$-a number of input vector.

The normalization conditions for $\mu_{j k}$, shown in $(3,4)$, are taken into account:

$$
\begin{aligned}
& \sum_{j=1}^{N} \mu_{j k}=1, \forall k=1, \ldots, K ; \\
& 0<\sum_{k=1}^{N} \mu_{j k} \leq K, \forall j=1, \ldots, N .
\end{aligned}
$$

A purpose of algorithm-minimization of sum of all weighted distances $\left\|x_{k}-c_{j}\right\|$ is shown in (5)

$$
\sum_{j=1}^{N} \sum_{k=1}^{K}\left(\mu_{j k}\right)^{q}\left\|x_{k}-c_{j}\right\| \rightarrow \min
$$

where $q$ is a fixed parameter, which is set before the iterations.

To achieve the above mentioned purpose it is necessary to solve the system of equations $(6,7)$ :

$$
\begin{aligned}
& \partial / \partial \mu_{j k}\left(\sum_{j=1}^{N} \sum_{k=1}^{K}\left(\mu_{j k}\right)^{q}\left\|x_{k}-c_{j}\right\|\right)=0 \\
& \partial / \partial c_{j}\left(\sum_{j=1}^{N} \sum_{k=1}^{K}\left(\mu_{j k}\right)^{q}\left\|x_{k}-c_{j}\right\|\right)=0
\end{aligned}
$$

Jointly with the normalization conditions $\mu_{j k}$ this system of differential equations has a solution in the form of (8) (weighted center of gravitation):

$$
c_{j}=\frac{\sum_{j=1}^{N}\left(\mu_{j k}\right)^{q} \cdot x_{k}}{\sum_{k=1}^{K}\left(\mu_{j k}\right)^{q}}
$$

and the new membership values are calculated by (9)

$$
\mu_{j k}=\frac{1 /\left\|x_{k}-c_{j}\right\|^{1 /(q-1)}}{\sum_{j=1}^{N}\left(1 /\left\|x_{k}-c_{j}\right\|^{1 /(q-1)}\right)}
$$

\section{Algorithm of fuzzy clustering is performed by the steps}

Step 1. Initialization.

The following parameters are chosen:

- required number of clusters $N, 2<N<K$;

- measure of distances, as the Euclidean distance;

- fixed parameter $q$ (usually 1.5);

- initial (at zero iteration) membership matrix

$U^{(0)}=\left(\mu_{j k}\right)^{(0)}$ of objects $x_{k}$ with taking into account the specified initial centers of clusters $c_{. j}$.

Step 2. Adjusting of the positions $c_{j}^{(t)}$ of clusters' centers.

At $t$-th iteration step with $\mu_{j k}^{(t)}$-the known matrix $c_{j}^{(t)}$ is calculated in accordance with afore-cited solution of the system of differential equations.

Step 3. Correction of membership values $\mu_{j k}$.

Taking into account the known $c_{j}^{(t)}, \mu_{j k}^{(t)}$ are calculated if $x_{k} \neq c_{j}$, otherwise:

$$
\mu_{j k}^{(t+1)}=\left\{\begin{array}{l}
1, l=j \\
0, \text { otherwise }
\end{array}\right.
$$

Step 4. Stop of algorithm.

Algorithm of fuzzy clustering stops when the following condition carries out:

$$
\left\|U^{(t+1)}-U^{(t)}\right\| \leq \varepsilon
$$

where || $\|$ - matrix norm (e.g. Euclidean norm);

$\varepsilon$ - predetermined level of accuracy.

On the presented methods the clustering of conditions of electric power industry's security for medium-term periods has been carried out, its results are shown in Table III.

TABLE III: RESULTS OF CLUSTERING OF ELECTRIC POWER INDUSTRY SECURITY STATES

\begin{tabular}{|c|c|c|c|c|c|}
\hline & \multicolumn{4}{|c|}{ Clusters' centers } & Radius \\
\hline subclust & 30,83 & 46,076 & 69,683 & 90,214 & 0,25 \\
\hline fcm & 29,774 & 43,207 & 68,664 & 89,891 & \\
\hline
\end{tabular}

As it is seen from Table III, the values of clusters' centers when clustering of the states of electric power industry security by subtractive algorithm and FCM-algorithm are very close; this allows concluding about the adequacy of the obtained results.

The similar calculations have also been carried out for clustering of states of electric power industry's security for long-term periods, and it has been revealed that with the adopted predicted values of indicators of electric power industry's security of Azerbaijan the number of states of electric power industry's security of Azerbaijan both for medium-term and for long-term periods constitutes four 
ones, but not five, as it has been indicated in the IEA studies. In this process the state of electric power industry's security $E$-"very bad" is excluded from the consideration, the occurrence probability of which for Azerbaijan under the assumed levels of indicators is extremely low (not one case in 18000), which is insufficient for organization of cluster.

The results of clustering of electric power industry's security states for medium-term periods are shown in Fig. 2.

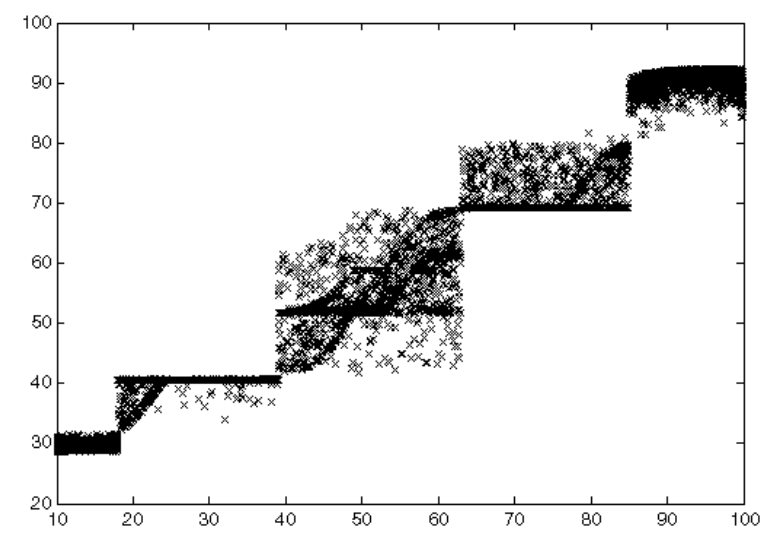

Fig. 2 Clusters of states of electric power industry's security

As it is seen from the figure $D$-"bad" state and $A$ "excellent" state occur not so often as $B-$-normal" state. The commonest occurring state of electric power industry's security of Azerbaijan for medium-term and long-term periods is the state of $C$-"not bad".

\section{CONCLUSION}

With the adopted predicted values of indicators of electric power industry's security of Azerbaijan the number of states of electric power industry's security of Azerbaijan both for medium-term and for the long-term periods constitute four ones, and not five, as it was indicated in the IEA studies.

The commonest occurring state of electric power industry's security of Azerbaijan for medium-term and longterm periods is the state $C$-"not bad."

\section{REFERENCES}

[1] V.Kh. Nasibov, "Application of the fuzzy-set theory to the tasks of Azerbaijan electric power industry security for short-term periods", Journal is registered in the library of the US Congress, USA, vol 9 № 4(35), pp. 37-50, 2014.

[2] V.Kh. Nasibov, "Determination of Azerbaijan electric power industry security for long-term periods on the basis of fuzzy deduction", Journal of Multidisciplinary Engineering Science Studies (JMESS), vol. 2 Issue 3, pp. 363-373, March 2016.

[3] Jessica Jewell, The IEA Model of Short-term Energy Security (MOSES). Primary Energy Sources and Secondary Fuels. International Energy Agency, Working Paper, 2011. Available: www.iea.org

[4] Design of Control Systems/ Fuzzy Logic Toolbox. Available: http://matlab.exponenta.ru/fuzzylogic/book2/1/subclust.php

[5] Clustering algorithms/Fuzzy clustering. Available: http://life-prog.ru/view_zam.php?id=89\&cat=5\%5C $\% 5 \mathrm{C} \% 5 \mathrm{C}$

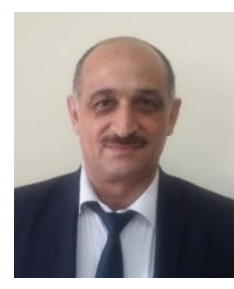

Nasibov Valeh was born in Djebrail region of Azerbaijan Republic on April 18, 1964. He graduated from the Moscow Energy Institute in 1987. In 2005 he was awarded a PhD's degree, in 2016 he became an assistant professor. Since 1987 to the present he has been working in Azerbaijani Scientific-Research Designed-Prospecting Institute of Energetics. From 2009 to 2012 he worked as the head of "Energy security" laboratory. Now he has become the head of "Perspective development the electricity" department. 